\title{
The Effect of Vitamin E Administration in Topical Olive Oil and Metamizole Injection on Plasminogen Activator Inhibitor-1 (PAI-1) Peritoneal Fluid and Degree of Adhesion
}

\author{
Wegig Perwiro Wibowo ${ }^{\text {aa*, Lulik Inggarwati }}{ }^{\mathrm{b}}$, Widanto $^{\mathrm{b}}$, \\ Setyo Sugiharto ${ }^{c}$, MS Niam $^{\mathrm{c}}$ \\ a wegigwibowo48@gmail.com

\begin{abstract}
${ }^{a}$ Resident Student in Department of Surgery, Faculty of Medicine Brawijaya University, Malang, East Java 65126, Indonesia
\end{abstract} \\ ${ }^{b}$ Surgeon consultant of pediatrician, Department of Surgery, Faculty of Medicine Brawijaya University, Malang, East Java 65126, \\ Indonesia

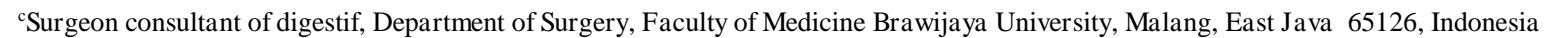

\begin{abstract}
Background and Purpose: Post-laparotomy adhesion is a problem for surgeons as well as patients. The purpose of this study was to establish a decrease in PAI-1 levels of peritoneal fluid, the degree of adhesion macroscopic and microscopically in male wistar rats subjected to ileum abrasion, between the combination of administration of vitamin E in topical olive oil and injection of Metamizole, single or unstained. Method: Laboratory experimental research. Using 24 male wistar rats which were subjected to ileum abrasion Relaparotomy was performed 14 days later to see the PAI-1 level of the peritoneal fluid, the degree of adhesion macroscopic and the degree of adhesion microscopically. Dataanalysis by ANOVA, Kruskal Wallis, and Spearman test. Result: There was a significant difference in peritoneal fluid PAI-1 levels in the P0-P3 group $(\mathrm{p}=0.036)$, but there was no significant difference in peritoneal fluid PAI-1 levels between P0-P1 ( $\mathrm{p}=0.761)$ and $\mathrm{P} 0-\mathrm{P} 2(\mathrm{p}=0.113)$. There was a significant difference in the P0-P3 group ( $\mathrm{p}=0.005)$, but there was no significant difference between P0-P2 $(\mathrm{p}=0.403)$ and $\mathrm{P} 0-\mathrm{P} 1(\mathrm{p}=0.187)$. Correlation test showed a significant correlation between PAI-1 levels of peritoneal fluid and the degree of macroscopic intraperitoneal adhesion with a large correlation of $r=0.750$ (macroscopic) and macroscopic intraperitoneal adhesion with a large correlation of $r=0.729$ (microscopic).Conclusion: Combination of vitamin $\mathrm{E}$ in topical olive oil with metamizole decrease in PAI-1 levels in peritoneal fluid, macroscopic and microscopic degree of adhesion.
\end{abstract}

Keywords: Adhesion, PAI-1, peritoneum, vitamin E, Metamizole, ileum abrasion, laparotomy

\section{Introduction}

Intraperitoneal adhesions are pathological bonds that usually occur between the omentum, bowel, and abdominal wall. This bond can be a thin layer of connective tissue, a thick fibrous joint containing blood vessels and nerves, or a direct adhesion between the two organs. Based on the etiology, intraperitoneal adhesions are divided into congenital and acquired, which can be inflammatory or postoperative. Intraperitoneal adhesions are generally caused by surgical procedures within the peritoneal cavity with a prevalence of 63\%-97\%. A survey in England in 1992 reported that annually there were 12,000 - 14,400 cases of obstruction caused by intestinal adhesions with colorectal surgery as the most common type of surgery.(Arung et al. 2013).

The incidence of adhesions in infants with omphalocele accompanied by small bowel obstruction in the first year is $12 \%$, gastrokisis is $27 \%$, incidence continues to increase to $15 \%$ in omphalocele after 10 years and to 37\% in gastroschisis.(Kadek Deddy Ariyanta, Dikki Drajat Kusmayadi 2020) In a study conducted in the Philippines, it was also mentioned that several diseases that can cause adhesions after laparotomy surgery are Hirschsprung's disease, malrotation, intestinal atresia, enterocolitis.(Deogracias \& Almonte 2019).

The incidence of obstruction caused by intraperitoneal adhesions in Indonesia is in the third position after inguinal hernia and colonic malignancy.(Obaid, 2011) The mortality rate due to small bowel adhesions ranges from 3\% in patients with simple obstruction while in patients with bowel perforation it ranges up to 30\%. (AlSalem and Oquaish, 2011) 
In a study conducted by Obaid in Malaysia, intestinal obstruction was found in 92 cases, of which $38 \%$ were caused by external hernias, $25 \%$ adhesions, $15.2 \%$ neoplasms, $8.6 \%$ volvulus, 5 intussusceptions, $4 \%$, and other causes as much as $2.17 \%$. Overall the percentage of obstruction in the small intestine is $73.9 \%$, while in the large intestine obstruction is $26.1 \%$.(Obaid, 2011)

The healing process of the peritoneum is different from the healing process of the skin, that is, if the inflammatory process and the initial phase of trauma have been resolved or can be removed, the fibrin formed will be re-decomposed by the process of fibrinolysis. The balance regulation in both processes is carried out by the role of cytokines. After pro-inflammatory cytokines work and the etiology of inflammation can be resolved, then these cytokines will decrease in concentration in the peritoneum because they are not produced again by cells involved in inflammation. Furthermore, the role of cytokines are cytokines that have an antiinflammatory function. These cytokines are IL-4 and IL-10. As a result of the increased concentration and activity of these cytokines, PA activity will increase, while PAI activity will be inhibited.(Deogracias and Almonte, 2019)

In general, the causes of adhesions are trauma, infection and tissue ischemia. The key to preventing adhesions after surgery is to selectively prevent factors that can cause adhesions. Fibrinolysis is the key to understanding the pathogenesis of adhesion, fibrinolysis plays a role in the occurrence of adhesion by breaking up fibrin clots that form during the healing process. Plasminogen is converted to plasmin by tissue plasminogen activator (t-PA) and urokinase-like plasminogen activator (uPA). The main role of plasmin is the degradation of fibrin, while the most dominant one that blocks this process from happening is Plasminogen activator inhibitor-1 (PAI-1), when PAI-1 is increased, the fibrinolysis process is disrupted so that adhesion is formed.(Kadek Deddy Ariyanta, Dikki Drajat Kusmayadi, 2020)

Until now there is no standard to prevent post-laparotomy intraperitoneal adhesions in children.(Deogracias and Almonte, 2019) The most effective way is to minimize the risk of adhesions with good surgical technique, handling and dissection of delicate tissues, careful homeostasis, avoiding extensive thermal trauma, adequate irrigation, avoiding exposure to foreign bodies (such as powder gloves and nonabsorbable sutures). and infection prevention. Even with the optimal surgical technique with regard to the rules mentioned above, it turns out that trauma to the peritoneum is still unavoidable so that the risk of adhesions also remains. Therefore, this study was conducted to minimize the risk of adhesions so that the incidence of morbidity can be reduced, of course with materials that are easily available and affordable.(Tang et al., 2020)

In vitro vitamin $\mathrm{E}$ has an effect as an anti-oxidant, anti-inflammatory, anti-coagulant, anti-fibroblastic, reducing collagen production.(Kadek Deddy Ariyanta, Dikki Drajat Kusmayadi, 2020) A study conducted by Corrales compared the effectiveness of topical intraperitoneal vitamin E, sodium hyaluronate. The results of his research prove that the effectiveness of vitamin $\mathrm{E}$ in preventing adhesion is the same as sodium hyaluronate.(Corrales et al., 2008) Research conducted by Agung from the University of Diponegoro which examined the decrease in TGF levels and the degree of adhesion using a combination of Vitamin $\mathrm{E}$ and olive oil topical with ketorolac also showed significant results in lowering TGF levels and reducing the degree of adhesion.(Agung Aji Prasetyo, 2018)

Metamizole is a non-steroidal anti-inflammatory drug (NSAID) which is commonly used in many countries, the role of metamizole to reduce adhesion formation is by inhibiting the Cyclooxygenase (COX) enzyme, where COX is an enzyme that catalyzes the synthesis of prostaglandins from arachidonic acid thereby inhibiting the synthesis and activation. prostaglandins, reduce platelet aggregation, decrease vascular permeability, and inhibit the activity of PMN cells, increase the function of macrophages as phagocytes, 
reduce the secretion of plasminogen inhibitors, prevent the formation and release of histamine and stabilize lysosomes.(Wu et al., 2021) In addition, the inhibition of the Cyclooxygenase (COX) enzyme causes the formation of free radicals.(Deogracias and Almonte, 2019)

If the results of research using vitamin $\mathrm{E}$ in topical olive oil and metamizole are proven to be effective in inhibiting adhesion, then it can qualify as an inexpensive and easy-to-obtain anti-adhesion agent. Therefore, further research is needed whether the use of these two ingredients alone or in combination can have a potentiating effect and further enhance its anti-adhesion effect.

Previously, research on prevention of adhesions had been conducted using a combination of Vitamin E in topical olive oil with Ketorolac Intramuscular, with the results of the study that there were significant results in the administration of a combination of Vitamin $\mathrm{E}$ in topical olive oil with Ketorolac Intramuscular.(Agung Aji Prasetyo, 2018) There is no study that combines the administration of vitamin E in topical olive oil and metamizole to see its effect on peritoneal fluid and the degree of adhesion.

\section{Methods}

This research is an experimental laboratory research, with a post test control design approach, using experimental animals wistar rats as research objects. The experiment was conducted with a simple randomized sampling design. There were 4 research treatments, namely control (P0), treatment 1 (P1), treatment $2(\mathrm{P} 2)$, treatment $3(\mathrm{P} 3)$. Research group division:

$\mathrm{P} 0 \rightarrow$ Control group, experimental animals were wistar rats with ileal abrasion.

$\mathrm{P} 1 \rightarrow$ Treatment group 1, Wistar rats were subjected to ileal abrasion and given vitamin E in intraperitoneal topical olive oil.

P2 $\rightarrow$ Treatment group 2, experimental animals were wistar rats with ileal abrasion and injection of metamizole $\mathrm{P} 3 \rightarrow$ Treatment group 3, experimental animals wistar rats were subjected to ileal abrasion and given vitamin $\mathrm{E}$ in intraperitoneal topical olive oil with metamizole injection.

\subsection{Research Implementation}

1) Twenty-four male wistar rats were adapted in the laboratory by being individually caged and given standard feed rations for 1 week ad libitum.

2) All mice were given the prophylactic antibiotic ceftriaxone $3 \mathrm{mg} / 100 \mathrm{gr}$ body weight intramuscularly 30 minutes before the first laparotomy to prevent infection.

3) Anesthesia using ketamine $50 \mathrm{mg} / \mathrm{kgBW}(15 \mathrm{mg}$ ), and diazepam $2.5 \mathrm{mg} / \mathrm{kgBW}$ intramuscularly. The procedure was carried out aseptically using sterile instruments.

4) Perform a laparotomy with a $5 \mathrm{~cm}$ midline incision, then open the peritoneum.

5) Identify the cecum and terminal ileum, and perform a $4 \mathrm{~cm}$ long abrasion on the terminal ileum until bleeding spots appear using a scalpel.

a. Group P0 (Treatment 0/no treatment), male wistar rats were subjected to ileal abrasion and not treated.

b. Group P1 (treatment 1), male wistar rats were subjected to ileal abrasion and given $10 \mathrm{mg}$ vitamin $\mathrm{E}$ dissolved in $5 \mathrm{ml}$ olive oil topically in the peritoneal cavity, above the site of the abrasion.

c. Group P2 (Treatment 2), male wistar rats were subjected to ileal abrasion and given Metamizole by Intramuscular (IM) $10-15 \mathrm{mg} / \mathrm{kgBW} /$ time (every $4-6$ hours) immediately after surgery.

d. Group P3 (Treatment 3), male wistar rats were subjected to ileal abrasion and given $10 \mathrm{mg}$ of vitamin E dissolved in $5 \mathrm{ml}$ of olive oil topically in the peritoneal cavity, above the place where the abrasion 
was done and given Metamizole by Intramuscular (IM ) 10-15 mg/kgBW/times (every 4-6 hours) immediately after surgery.

6) The surgical wound was closed with single layer sutures using 3/0 silk, without suturing the peritoneum.

7) After surgery, male wistar rats were treated in their original cages and separated to reduce the risk of rats being injured due to the aggressiveness of other rats.

8) A relaparotomy was performed on day 14 to assess the degree of intraperitoneal adhesion. Previously, wistar rats were anaesthetized and given PBS $10 \mathrm{x}$ as much as $3 \mathrm{cc}$ through an incision $\pm 0.5 \mathrm{~cm}$ right side of the median line, and massaged the abdomen for 90 seconds, then wistar rats were positioned at an angle of $45 \mathrm{o}$ with the head up for 5 minutes so that the peritoneal fluid collected in the cavity. pelvis. The second laparotomy incision was performed in a 45 o tilted position with the head up, this was done to facilitate the collection of peritoneal fluid, and to assess adhesions on the left side (terminal ileum). Peritoneal fluid was taken as much as \pm 1 cc for PAI- 1 assessment.

9) PAI-1 inspection procedures:

1) Prepare tools and reagents.

2) Standard concentration of PAI-1 rat was prepared by mixing diluent F sample and standard solution containing $10 \mathrm{ng} / \mathrm{mL}$ PAI-1 rat.

3) The peritoneal fluid sample was dilated 2 times (1:2) with a diluent sample.

4) Microwell prepared, then enter the reagent into it according to the steps below:

a. Add to each microwell 100 L Anti Rat PAI-1 HRP Conjugate

b.Add $100 \mathrm{~L}$ of PAI-1 standard and the diluted sample to each microwell in order

c. Incubation for 2 hours at room temperature $(18-250 \mathrm{C})$

d.Add $0.45 \mathrm{M} \mathrm{H} 2 \mathrm{SO} 450 \mathrm{~L}$ to stop the reaction

e. Wait for 10 minutes for the color to stabilize

5) Take a microwell reading on an ELISA plate reader with a wavelength of $450 \mathrm{~nm}$.

10) The procedure for microscopic examination of the paraffin block method

1) Take a fresh sample of tissue that has $\pm 1 \mathrm{~cm}$ long adhesions.

2) Tissue fixation in 10\% buffered neutral formalin solution (1:10 organ and solution ratio).

3) Drain the tissue, then cut the tissue sample with a thickness of $0.3-0.5 \mathrm{~mm}$ using a scalpel and arranged into a tissue cassette.

4) Then the dehydration process was carried out by inserting the sample on a tissue cassette into an automatic processor machine for 2 hours.

5) Then the vacuum process is carried out to remove air from the tissue for 30 minutes.

6) Printing paraffin blocks using a mold made of Stainless steel which is warmed on a bunsen then insert the tissue into each mold. Pour liquid paraffin that has been heated to a temperature of $600 \mathrm{C}$ into the network until the entire network is submerged in paraffin, the paraffin is allowed to freeze on the cooling machine. Furthermore, the paraffin block is removed from the mold and stored in the freezer (-200C) before cutting.

7) Cut the paraffin block containing the tissue using a microtome machine with a thickness of $\pm 3-4 \mathrm{~m}$, then the pieces are placed in a water bath at $460 \mathrm{C}$. Then trim the slices and place them on a glass slide that has been smeared with ewith which functions as an adhesive.

8) Arrange the slide with the tissue on it on a special shelf and put it in an incubator with a temperature of $600 \mathrm{C}$.

9) The process of coloring and identification.

\subsection{Data Analysis Method}

The data analysis method in this study is described as follows:

1) Descriptive analysis in the form of the average value and standard deviation, as well as graphs to be more informative. 
2) Hypothesis testing 1 to 3 was carried out with different tests (Analysis of Variance / ANOVA for PAI-1 levels and Kruskall Wallis test for the degree of intraperitoneal adhesion)

3) Hypothesis 4 testing was carried out by using Sperman rank correlation analysis

4) The analysis process is carried out with the help of SPSS Software

\section{Results}

A macroscopic picture is obtained in picture adhesion grade 1-4 in Figure 1-4, and for microscopic in Figure 5-8. The statistical results from the descriptive average (mean) levels of PAI-1 levels of peritoneal fluid in the P0 group were $7.3140 \pm 0.7414 \mathrm{ng} / \mathrm{mL}$; in the P1 group was $6.5385 \pm 2.0968 \mathrm{ng} / \mathrm{mL}$; in the P2 group it was $5.4318 \pm 1.4635 \mathrm{ng} / \mathrm{mL}$ and in the $\mathrm{P} 3$ group it was $4.9795 \pm 0.6290 \mathrm{ng} / \mathrm{mL}$.It was found that the mean PAI-1 levels of peritoneal fluid were decreasing in groups P1, P2, P3 compared to groups P0 (table 1). Statistical analysis to determine the difference in PAI-1 levels of peritoneal fluid between the treatment groups, the data normality test was performed using the Shapiro-Wilk test (table 2).

The results of the normality test output PAI-1 concentration of peritoneal fluid $(\mathrm{ng} / \mathrm{mL})$ in groups P0, P1, P2 and P3 data were normally distributed because each sig value was p>0.05, so a mean difference test between groups could be performed. The homogeneity of variance test used the "homogeneous of variance" test with a significance value of $\mathrm{p}>0.05$, so it can be said that the variance between groups was not significantly different, therefore statistical analysis of the different PAI-1 levels of peritoneal fluid used ANOVA. The analysis was continued with Tukey's post hoc test (table 3). Analysis of the degree of macroscopic adhesion in each group using the Kruskal Wallis test and the result significant $\mathrm{p}=0.016$ for macroscopic and microscopic $\mathrm{p}=0.011$ (table 4).

The correlation between PAI-1 levels and the degree of macroscopic and microscopic intraperitoneal adhesions was tested using the Spearman correlation. The results obtained (table 6) show ap value $=0.000$ in the relationship of PAI-1 with the degree of macroscopic intraperitoneal adhesion and ap value $=0.001$ in PAI-1 with the degree of microscopic intraperitoneal adhesion.

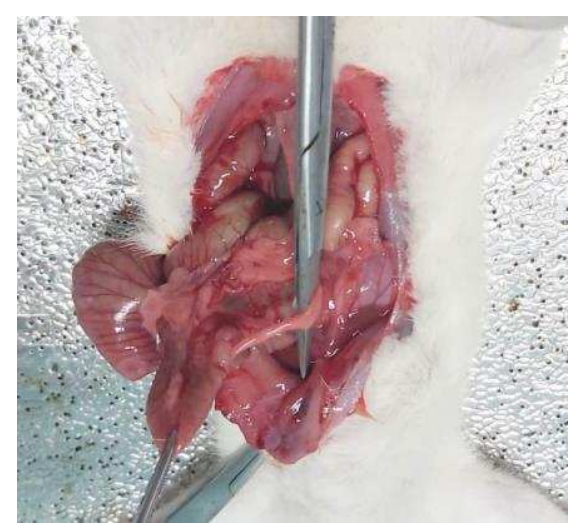

Figure 1 Adhesion degree I (Macroscopic)

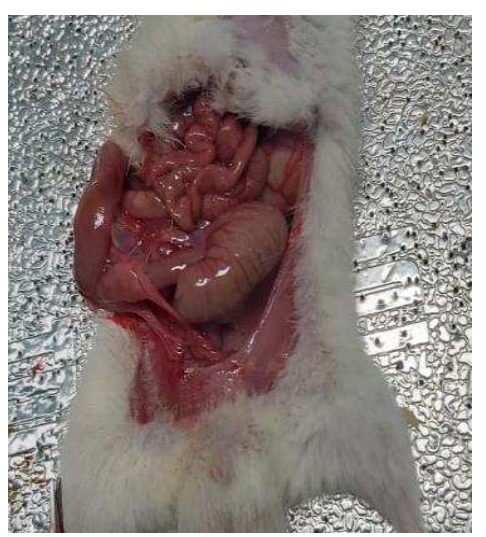

Figure 2 Adhesion grade II (Macroscopic) 


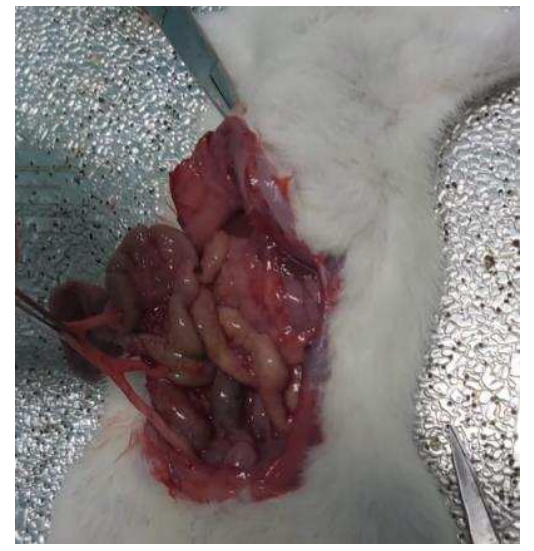

Figure 3. Adhesion grade III (Macroscopic)

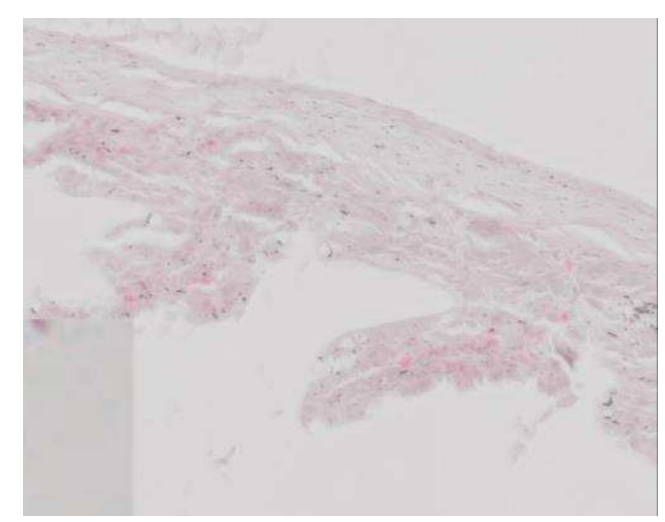

Figure 5. Adhesion grade 0 (Microscopic)

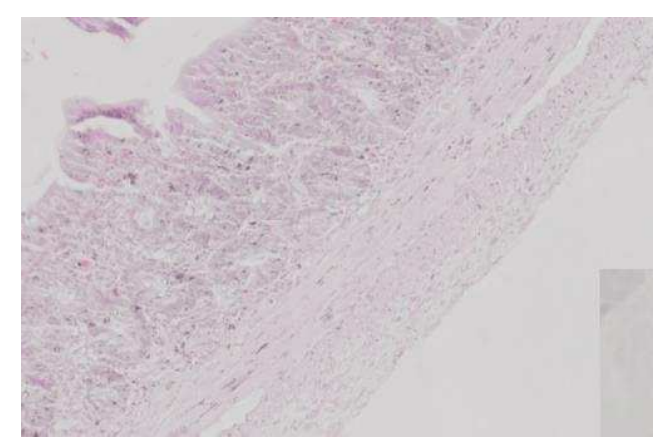

Figure 7 Adhesion grade II (Microscopic)

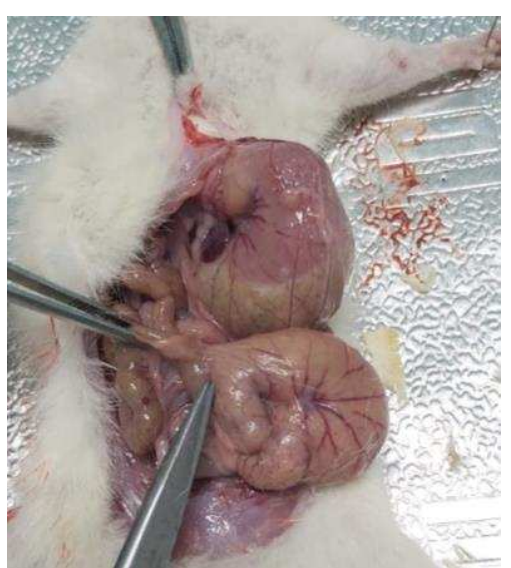

Figure 4 Adhesion grade IV (Macroscopic)

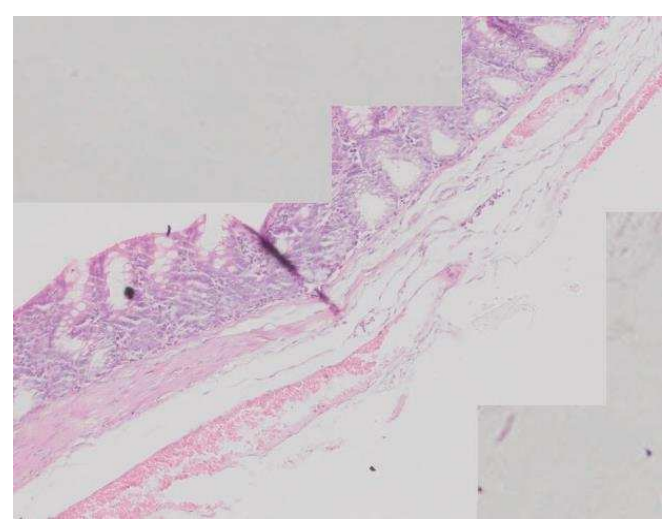

Figure 6. Adhesion grade I (Microscopic)

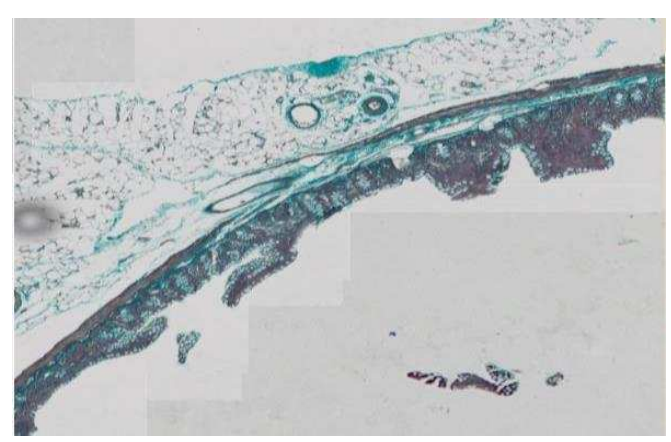

Figure 8 Adhesion grade III mason's trichrome (+) (Microscopic) 
Table 1. Descriptive value of PAI-1 levels in peritoneal fluid

\begin{tabular}{lll}
\hline \multicolumn{1}{c}{ Group } & N & \multicolumn{1}{c}{ Average \pm SB } \\
\hline P0 (Control) & 6 & $7.3140 \pm 0.7414 \mathrm{ng} / \mathrm{mL}$ \\
P1 (Vitamin E + Olive Oil) & 6 & $6.5385 \pm 2.0968 \mathrm{ng} / \mathrm{mL}$ \\
P2 (Metamizole) & 6 & $5.4318 \pm 1.4635 \mathrm{ng} / \mathrm{mL}$ \\
P3 (Vitamin E + olive oil with Metamizole) & 6 & $4.9796 .6290 \mathrm{ng} / \mathrm{mL}$ \\
\hline
\end{tabular}

Table 2. Shapiro-Wilk. Normality and Homogeneity Test

\begin{tabular}{|c|c|c|c|c|c|}
\hline & \multirow[t]{2}{*}{ Group } & \multicolumn{3}{|c|}{ Shapiro-Wilk } & \multirow{2}{*}{$\frac{\text { Levene Statistics }}{\text { Sig }}$} \\
\hline & & $\begin{array}{l}\text { Statisti } \\
\text { cs }\end{array}$ & df & Sig. & \\
\hline \multirow{4}{*}{$\begin{array}{l}\text { ConcentrationPAI-1 } \\
\text { peritoneal fluid }(\mathrm{ng} / \mathrm{mL})\end{array}$} & $\mathrm{P} 0$ & .829 & 6 & 0.106 & \multirow[t]{4}{*}{0.123} \\
\hline & $\mathrm{P} 1$ & .962 & 6 & 0.836 & \\
\hline & $\mathrm{P} 2$ & .822 & 6 & 0.091 & \\
\hline & P3 & .952 & 6 & 0.757 & \\
\hline
\end{tabular}

Table 3. P-value Post Hoc Tukey PAI-1 levels of peritoneal fluid

\begin{tabular}{lcccc}
\hline Variable & $(\mathrm{P} 0)$ & $(\mathrm{P} 1)$ & $(\mathrm{P} 2)$ & $(\mathrm{P} 3)$ \\
\hline Control (P0) & - & 0.761 & 0.113 & 0.036 \\
Vitamin E in topical olive oil (P1) & & - & 0.513 & 0.231 \\
Metamizole (P2) & & - & 0.939 \\
Vitamin E in olive oil topical + & & - \\
Metamizole (P3) & & \\
*. The mean difference is significant at the 0.05 level. & &
\end{tabular}

Table 4. Distribution of the results of measuring the degree of macroscopic and microscopic adhesion in each group and the results of the Kruskal Wallis test

\begin{tabular}{|c|c|c|c|c|c|}
\hline Grade & $\mathrm{P} 0$ & $\mathrm{P} 1$ & $\mathrm{P} 2$ & $\mathrm{P} 3$ & p Nilai value \\
\hline \multicolumn{6}{|c|}{ Macroscopic } \\
\hline 0 & 0 & 0 & 2 & 4 & 0.016 \\
\hline 1 & 1 & 2 & 1 & 2 & \\
\hline 2 & 1 & 0 & 0 & 0 & \\
\hline 3 & 1 & 3 & 2 & 0 & \\
\hline 4 & 3 & 1 & 1 & 0 & \\
\hline median \pm Range & $3 \pm 1.27$ & $2.5 \pm 1.22$ & $1.83 \pm 1.72$ & $0.33 \pm 0.51$ & \\
\hline \multicolumn{6}{|c|}{ Microscopic } \\
\hline 0 & 0 & 0 & 2 & 3 & 0.011 \\
\hline 1 & 0 & 1 & 1 & 2 & \\
\hline 2 & 1 & 3 & 1 & 1 & \\
\hline 3 & 5 & 2 & 2 & 0 & \\
\hline median \pm Range & $2.83 \pm 0.41$ & $2.17 \pm 0.75$ & $1.5 \pm 1.38$ & $0.67 \pm 0.82$ & \\
\hline
\end{tabular}


Table 5 Mann Whitney test for the degree of macroscopic and microscopic intraperitoneal adhesions

\begin{tabular}{|c|c|c|c|c|}
\hline Variable & $(\mathrm{P} 0)$ & $(\mathrm{P} 1)$ & $(\mathrm{P} 2)$ & (P3) \\
\hline \multicolumn{5}{|c|}{ Macroscopic } \\
\hline Control (P0)\ & - & 0.403 & 0.187 & 0.005 \\
\hline Vitamin E in topical olive oil (P1) & & - & 0.450 & 0.007 \\
\hline Metamizole (P2) & & & - & 0.120 \\
\hline Vitamin E in olive oil topical + Metamizole (P3) & & & & - \\
\hline \multicolumn{5}{|c|}{ Microscopic } \\
\hline Control (P0)\ & - & 0.083 & 0.060 & 0.003 \\
\hline Vitamin E in topical olive oil (P1) & & - & 0.405 & 0.016 \\
\hline Metamizole (P2) & & & - & 0.275 \\
\hline Vitamin E in olive oil topical + Metamizole (P3) & & & & - \\
\hline
\end{tabular}

Table 6. Spearman Rank Correlation

\begin{tabular}{|c|c|c|c|}
\hline & & $\begin{array}{l}\text { Macroscopic degree of } \\
\text { adhesion }\end{array}$ & $\begin{array}{l}\text { Microscopic degree of } \\
\text { adhesion }\end{array}$ \\
\hline \multirow{3}{*}{ PAI-1 . levels } & $\mathrm{R}$ & 0.750 & 0.729 \\
\hline & $\mathrm{P}$ & 0.000 & 0.001 \\
\hline & Direction & + and tight & + and tight \\
\hline
\end{tabular}

\section{Discussion}

The results of statistical tests showed that the combination of vitamin $\mathrm{E}$ in intraperitoneal topical olive oil with metamizole would significantly reduce PAI-1 levels of peritoneal fluid compared to controls, but there was no significant difference when compared to single administration of vitamin $\mathrm{E}$ in intraperitoneal topical olive oil or administration of metamizole alone. Likewise, the results of statistical tests on the degree of intraperitoneal adhesion macroscopically and microscopically showed that the combination of vitamin $\mathrm{E}$ in intraperitoneal topical olive oil with metamizole could significantly reduce the degree of adhesion both macroscopically and microscopically.

In vitro vitamin $\mathrm{E}$ has an effect as an anti-oxidant, anti-inflammatory, anti-coagulant, anti-fibroblastic, reducing collagen production.(Kadek Deddy Ariyanta, Dikki Drajat Kusmayadi, 2020) In vivo Vitamin E can reduce lipid peroxidation which plays a role in the mechanism of cell or tissue damage due to free radical attack.(Corrales et al., 2008)A study conducted by Corrales compared the effectiveness of topical intraperitoneal vitamin E, sodium hyaluronate. Corrales uses vitamin E $10 \mathrm{mg}$ (fat soluble) dissolved in 5cc olive oil administered topically intraperitoneally. Olive oil is used as a dilution vehicle. Corales used 60 wistar rats to compare the effectiveness of topical intraperitoneal vitamin $\mathrm{E}$ and sodium hyaluronate. The results of his research prove that the effectiveness of vitamin $E$ in preventing adhesion is the same as sodium hyaluronate.(Corrales et al., 2008) Vitamin E also has anti-inflammatory, anti-coagulant effects, inhibits thrombus formation, and can inhibit the activity of TGF- (a strong fibrosis inductor) and can reduce collagen production.(Agung Aji Prasetyo, 2018)

The use of vitamin E in topical olive oil was previously investigated by Hermawan in 2012 who examined the combination of giving vitamin $\mathrm{E}$ in topical olive oil with oral simvastatin on the degree of adhesion, the study found that the combination of vitamin $\mathrm{E}$ in topical olive oil with simvastatin can significantly reduced the degree of adhesion and PAI-1 levels compared to single administration of vitamin E in topical olive oil or single administration of simvastatin.(Kadek Deddy Ariyanta, Dikki Drajat Kusmayadi, 2020) Another study 
using vitamin $\mathrm{E}$ in olive oil was conducted by Haidar who combined the administration of vitamin $\mathrm{E}$ in topical olive oil with omega-3 which was shown to reduce the degree of intraperitoneal adhesion.(Tang et al., 2020) Research that has been done before using non-steroidal anti-inflammatory drugs. Another type, namely ketorolac and vitamin E in topical olive oil conducted in Semarang, it was found that there was a significant difference in the degree of adhesion to the combination of ketorolac and vitamin $\mathrm{E}$ in topical olive oil, but there was no significant difference between the single administration of ketorolac and vitamin $\mathrm{E}$ in olive oil. Topical.(Agung Aji Prasetyo, 2018) Research conducted by Portilla reported that there was a significant reduction in adhesion formation with a single administration of vitamin E in topical olive oil.(De La Portilla et al., 2004) However, in another study, it was found that the administration of vitamin E did not affect the occurrence of intraperitoneal adhesions, only reduced its severity. In a study conducted by Corrales olive oil in a single administration, there were no significant results in reducing the occurrence of intraperitoneal adhesions.(Corrales et al., 2008)

The mechanism of metamizole to reduce adhesion formation is by inhibiting the enzyme Cyclooxygenase $(\mathrm{COX})$ is an enzyme that catalyzes the synthesis of prostaglandins from arachidonic acid thereby inhibiting the synthesis and activation of prostaglandins, reducing platelet aggregation, reducing vascular permeability, and inhibiting the activity of PMN cells, increasing macrophage function. as phagocytes, reduce the secretion of plasminogen inhibitors, prevent the formation and release of histamine and stabilize lysosomes. (Croes and Vanegas, 2008) In addition, the inhibition of the Cyclooxygenase (COX) enzyme causes the formation of free radicals.(Deogracias and Almonte, 2019) Research that has been done before using non-steroidal antiinflammatory drugs. Another type is ketorolac.

Based on the mechanism described above, the administration of a combination of vitamin $\mathrm{E}$ in topical olive oil and injection metamizole proved to be significant in reducing PAI-1 levels of peritoneal fluid, macroscopic degree of adhesion and microscopic degree of adhesion compared to control or single administration of metamizole injection or vitamin E. in topical intraperitoneal olive oil. This indicates that the treatment of administration of vitamin $\mathrm{E}$ in topical intraperitoneal olive oil with metamizole injection is the best.

The correlation between PAI-1 levels with the microscopic degree of adhesion and the degree of macroscopic adhesion was tested using the Spearman test. The results of the test showed that there was a significant correlation between PAI-1 levels and the degree of macroscopic and microscopic intraperitoneal adhesions, meaning that if PAI-1 levels of intraperitoneal fluid increased, the degree of adhesion also increased.

Research to prevent intraperitoneal adhesions by using a combination of vitamin $\mathrm{E}$ in intraperitoneal topical olive oil with metamizole can be recommended for further animal studies with other doses and methods of administration in the hope of obtaining better results than the research that has been done so that its use is expected to be used as an alternative. practical application in surgery.

\section{Conclusion}

Combination of vitamin $\mathrm{E}$ in topical olive oil with metamizole decrease in PAI-1 levels in peritoneal fluid, macroscopic and microscopic degree of adhesion. This research is recommended for further experimental animal studies with other doses and methods of administration in the hope of obtaining better results so that their use is expected to be used as a practical application in surgical procedures. 
Author Contributions: Conceptualization, W.P.W, L.I; methodology, W.P.W, L.I, W, S.S, M.S.N.; software,W.P.W; validation, W.P.W, L.I, W, S.S, and M.S.N.; formal analysis, W.P.W; investigation, W.P.W, L.I, W, S.S, M.S.N.; resources, W.P.W, L.I, W, S.S, M.S.N.; data curation, W.P.W.; writing-original draft preparation, W.P.W; writing-review and editing, W.P.W, L.I, W, S.S, and M.S.N.; visualization, W.G; supervision, L.I, W, S.S, M.S.N; project administration, L.I, W, S.S, M.S.N.; funding acquisition, L.I, W, S.S, M.S.N. All authors have read and agreed to the published version of the manuscript.

\section{Competing interests}

No competing interests were disclosed.

\section{Conflict of interest}

The authors declare no conflict of interest, financial or otherwise.

\section{Acknowledgments}

declared none.

\section{References}

Agung Aji Prasetyo, 2018. Pengaruh Pemberian Kombinasi Vitamin E Dalam Olive Oil Topikal Dengan Ketorolac Intramuskular Terhadap Kadar Tgf B Cairan Peritoneum Dan Derajat Adhesi. Univ. diponegoro.

Al-Salem, A.H., Oquaish, M., 2011. Adhesive Intestinal Obstruction in Infants and Children: The Place of Conservative Treatment. ISRN Surg. 2011, 1-4. https://doi.org/10.5402/2011/645104

Arung, W., Jehaes, F., Cheramy, J.P., Defraigne, J.O., Meurisse, M., Honoré, P., Drion, P., Detry, O., 2013. Effects of parecoxib on the prevention of postoperative peritoneal adhesions in rats. J. Investig. Surg. 26, 340-346. https://doi.org/10.3109/08941939.2013.810316

Corrales, F., Corrales, M., Schirmer, C.C., 2008. Preventing intraperitoneal adhesions with vitamin E and sodium hyaluronate/carboxymethylcellulose. A comparative study in rats. Acta Cir. Bras. 23, 36-41. https://doi.org/10.1590/S010286502008000100007

Croes, R., Vanegas, M., 2008. Cointegration and causality between tourism and poverty reduction. J. Travel Res. 47, 94-103. https://doi.org/10.1177/0047287507312429

De La Portilla, F., Ynfante, I., Bejarano, D., Conde, J., Fernández, A., Ortega, J.M., Carranza, G., 2004. Prevention of peritoneal adhesions by intraperitoneal administration of vitamin E: An experimental study in rats. Dis. Colon Rectum 47, $2157-2161$. https://doi.org/10.1007/s10350-004-0741-6

Deogracias, J.M.C., Almonte, J.R., 2019. Postoperative adhesions after abdominal surgery in children: A pilot study in the Philippines. World J. Pediatr. Surg. 2, 2-6. https://doi.org/10.1136/wjps-2019-000049

Kadek Deddy Ariyanta, Dikki Drajat Kusmayadi, R.D., 2020. Perbedaan Kadar Plasminogen Activator Inhibitor-1 Cairan Peritoneum Tikus Wistar Antara Yang Diberi Vitamin E The Differences Of Plasminogen Activator Inhibitor-1 Level In Peritoneum Fluid Among Rats Given Topical Vitamin E Or Intramuscular. Open Access Emerg. Med. 1.

Obaid, K.J., 2011. Intestinal Obstruction: Etiology , Correlation between Pre- Operative and Operative Diagnosis. Int. J. Public Heal. Res. Spec. Issue 41-49.

Tang, J., Xiang, Z., Bernards, M.T., Chen, S., 2020. Peritoneal adhesions: Occurrence, prevention and experimental models. Acta Biomater. 116, 84-104. https://doi.org/10.1016/j.actbio.2020.08.036

Wu, Y., Li, E., Wang, Z., Shen, T., Shen, C., Liu, D., Gao, Q., Li, X., Wei, G., 2021. TMIGD1 Inhibited Abdominal Adhesion Formation by Alleviating Oxidative Stress in the Mitochondria of Peritoneal Mesothelial Cells. Oxid. Med. Cell. Longev. 2021. https://doi.org/10.1155/2021/9993704 